\title{
Assessment of Biological Activity and Comparison of UPLC and RP-HPLC Chromatographic Profiles of Clausena excavata Burm.F.
}

\author{
Guntupalli Chakravarthi ${ }^{1 *}$, Alavala Rajasekhar Reddy ${ }^{2}$, Maddi Ramaiah ${ }^{3}$
}

Guntupalli Chakravarthi ${ }^{1 *}$, Alavala Rajasekhar Reddy², Maddi Ramaiah $^{3}$

1,2Department of Pharmacy, K L University, Vaddeswaram, Guntur, A. P. India-522502

${ }^{3}$ Department of Pharmacognosy \& Phytochemistry, Hindu College of Pharmacy, Amaravathi Road, Guntur, A.P. India-522002

\section{Correspondence}

G. Chakravarthi,

$K L$ College of Pharmacy,

K L University, Vaddeswaram,

Guntur, A. P. India - 522502

Phone no: +91-8374138048

E-mail: chakra_varthi123@kluniversity.in

\section{History}

- Submission Date: 12-12-2016;

- Review completed: 18-12-2016;

- Accepted Date: 04-01-2017.

DOI : 10.5530/pj.2017.2.30

Article Available online

http://www.phcogj.com/v9/i2

\section{Copyright}

(c) 2017 Phcog.Net. This is an openaccess article distributed under the terms of the Creative Commons Attribution 4.0 International license.

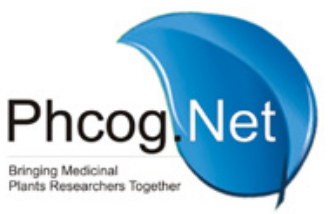

\begin{abstract}
Clausena excavata Burm. F. (Rutaceae) has long been associated with medicinal benefits in folk medicine, particularly in the treatment of cancer and its related disorders in the eastern region of Thailand. In the the present study Ultra Pressure Liquid Chromatography (UPLC) analysis of methanolic leaf extracts of Clausena excavata were carried out using short $(5 \mathrm{~cm} \times 2.1 \mathrm{~mm}$ I.D.) columns, containing $2 \mu \mathrm{m}$ particles at very high pressures (up to $16000 \mathrm{psi}$ ) to obtain high efficiency separations in very short run times. The results indicate that UPLC provided better resolution compared to routine RP-HPLC. The analysis time was drastically reduced (4 min.) which is proved to be a faster and more economical analytical tool than RP-HPLC. In addition to that, the present study also evaluates anti-fungal activity against dermatophytes Trichophyton rubrum and Trichophyton mentographytes by using an agar incorporation technique. The anti-fungal activity may be due to the presence of Angelecin and gallic acid in the plant extract.
\end{abstract}

Key words: UPLC, Clausena, Angelecin, HPLC, Rutaceae.

\section{INTRODUCTION}

Ethno botanical screening of species of the Rutaceae family in several continents has shown that they have important medicinal properties. Clausena excavata is a wild shrub of the Rutaceae family that is distributed in South Asia. It is also cultivated in some areas and grows up to $1.5 \mathrm{~m}$ high. It has been used in folk medicine for the treatment of cancer and several disorders in the eastern parts of Thailand. ${ }^{1-4}$ Its leaves and stem are also used to treat colic, cough, headache, ${ }^{3}$ rhinitis, sore, wounds, and yaws, and it is used for detoxification in some countries. ${ }^{3}$

The leaves are particularly used in traditional medicine to cure cold, abdominal pain, malaria, ${ }^{5}$ dysentery, and anti-platelet aggregation. ${ }^{6}$ The plant is also reported to have insecticidal, tonic, and vermifugal properties. ${ }^{6}$ C. excavata has been reported to contain carbozole alkaloids, coumarins, limnoids, ${ }^{4}$ etc. The sap of the leaves is applied on the affected area to treat all kinds of muscular pain. ${ }^{3}$ A decoction of the root is given to patients with malaria; ${ }^{5}$ an infusion of the stem is given in patients with colic. The leaves and stem bark are also used locally as a diuretic, tonic, astringent, and antinociceptive agent. ${ }^{3}$ The coumarins derived from the leaves have been found to have inhibitory effects on tumor progression..$^{7-8}$

Several researchers have been identified-phenylpropanoids, ${ }^{9}$ methoxyflavones, ${ }^{10}$ furoquinoline alkaloids, ${ }^{11}$ coumarins, ${ }^{12}$ and acridone alkaloids. ${ }^{13}$ However, the chemical components of species of this family Several pharmacologically active constituents of plants belonging to the family Rutaceae are yet to be fully elucidated. We chose to study the phytochemical properties of three methanolic rutaceous extracts because it is known to have antioxidant properties. Cellular damage arising from reactive oxygen species (ROS) has been shown to play a part in the development and pathophysiology of neurodegenerative disorders (e.g., Alzheimer disease, Parkinson disease, multiple sclerosis, and Down syndrome), inflammation, viral infections, autoimmune pathologies, and digestive system disorders such as gastrointestinal inflammation and ulcer. ${ }^{14}$ We therefore focused our investigation on the anti-fungal potential of methanolic rutaceous extracts and isolated constituents.

The aim of the present investigation was to separate, characterize, and identify the major chemical constituents of three rutaceous methanolic extracts and to explore the anti-fungal potential of its methanolic extracts and isolated constituents to determine the minimum inhibitory concentration of (MIC) of crude plant extracts and isolated components against dermatophytes, Trichophyton rubrum and Trichophyton mentographytes by using an agar incorporation technique ${ }^{15}$ and compare the chromatographic profile of Ultra Performance Liquid Chromatography and RP-HPLC methods.

\section{MATERIALS AND METHODS}

\section{Plant material}

Leaves of three rutaceous extracts were collected from the northern regions of Malaya and their identity was further authenticated by Bowen, from the Department of Pharmacognosy, University of Sunderland, and a voucher specimen sample was deposited in the herbarium. The collected plant material was dried well under shade and powdered using electric blender. 


\section{Reagents, equipment and organisms}

Disposable $30 \mathrm{ml}$ plastic universal containers were used. Sterile petri dishes (compartmentalized) were used for preparation of test plates. Dimethylsulphoxide (Fisher Chemicals) was used as solvent control in this experiment. Purified water $\mathrm{pH} 7.3$ and Maximum Recovery Diluent (Thermo Scientific Oxoid CM733) were also used. Vortex mixer was used for the homogenization of extract solution. Automatic multichannel pipettes Eppendorf, sterile tips $200 \mu \mathrm{l}$, sterile plastic $5 \mathrm{ml}$ and $10 \mathrm{ml}$ pipettes for transfer of inoculum into the Petri dishes were used. Sabouraud Dextrose Agar (SDA) (Oxoid CM41) pH 5.55 was used as a medium for the dermatophyte growth. Griseofulvin (97\%) (Acros Organics) was used as standard drug. T. rubrum, T. mentagrophytes, Epidermatophyton floccusum and Candida albicans were used as test organism.

\section{Soxhlet extraction (Preparation of crude extract)}

The powdered leaf material (100 g) was successively extracted with petroleum ether, hexane, chloroform, dichloromethane, ethanol, and water. The volume of the solvent used in each case was $500 \mathrm{ml}$. Before extraction with each solvent, the powdered material was air dried and weighed. The largest quantity of extract was obtained with methanol. Further fractionation of the extracts was therefore carried out on the methanolic leaf extract by high-performance liquid chromatography and UPLC.

\section{Preparation of extract dilution series}

Extract stock solution: $200 \mathrm{mg}$ crude plant extract was dissolved in 10 $\mathrm{ml}$ dimethyl sulfoxide (DMSO) with glass beads. Vortex was used to homogenize the extract solution. Dilution series: $5 \mathrm{ml}$ of stock solution was pipetted into $5 \mathrm{ml}$ of purified water. It was vortexed for 30 seconds. Doubling dilutions were repeated with successive $5 \mathrm{ml}$ aliquots of purified water.

\section{Preparation of dermatophyte inoculum}

Using a 7-10-day culture of dermatophyte, grown on SDA at $30^{\circ} \mathrm{C}$, enough $0.45 \%$ saline solution was added onto the surface of the growth and then gently agitated with the tip of a sterile cotton swab to create a suspension and the spore concentration was determined with the aid of a Neubar hemocytometer. From the stock suspension, dilutions in maximum recovery diluent were performed. In order to achieve a final concentration of $1 \mathrm{x} 106 \mathrm{cfu} / \mathrm{ml} .20 \mu \mathrm{l}$ (equivalent to $2 \mathrm{x} 104 \mathrm{cfu} / \mathrm{ml}$ ) of inoculum was used.

\section{Preparation of test plates}

A suitable number of sterile $9 \mathrm{ml}$ aliquots of molten Sabouraud Dextrose Agar (SDA), were prepared in $30 \mathrm{ml}$ glass universals (temperature held at $50-55^{\circ} \mathrm{C}$ ). To each SDA aliquot, $1 \mathrm{ml}$ of extract dilution was added and then gently inverted to mix (without introducing air bubbles). For each series of extract/agar suspensions several double-compartment plastic petri dishes were suitably labelled. Into one-half of the petri dish (compartment) the extract/agar suspension was added. The plates were left to set for 30 minutes at room temperature. Each plate was dried under laminar flow for 5-10 minutes with lid open and stored in the fridge for future use.

\section{Inoculation of test plates}

From each dermatophyte working suspension a $20 \mathrm{ml}$ aliquot was pipetted onto the agar surface of each petri-dish compartment. Each compartment had two aliquots representing the two different dermatophytes. Plates were left to absorb the dermatophyte spore. Once dry, plates were inverted and incubated at $30^{\circ} \mathrm{C}$ for minimum of 4 days or until growth was seen on control plates. Plates were incubated in loosely bound plastic bags to prevent excessive moisture loss.

\section{Controls}

\section{TVAC control}

A serial pour plate method, with SDA, was used to determine total viable aerobic Count (TVAC) of dermatophyte stock suspension. The plates were incubated along with test samples. (To demonstrate sufficient organism concentration).

Media controls (for each batch of media used): SDA plates (without extract dilution or dermatophyte) were incubated along with the test sample (to demonstrate media sterility). SDA plates (without extract dilution) were inoculated with dermatophytes, as in the test procedure, and incubated along with the test samples. (To demonstrate media suitability and organism viability within the test system).

\section{Solvent control}

Series of plates using dilutions of DMSO (without extract) were prepared according to test procedure. Plates were incubated along with test samples. (To demonstrate lack of solvent interference).

\section{Antibiotic/ process control}

MIC of griseofulvin was determined during every experiment. A stock solution of griseofulvin in DMSO was prepared $(1000 \mathrm{~g} / \mathrm{ml})$. This was diluted in purified water to produce a doubling dilution series and plates prepared according to the test procedure (concentrations: 0.2 to $100 \mu \mathrm{g}$ / $\mathrm{ml}$ ) and incubated along with test samples. (To demonstrate process repeatability between day-to-day testing and comparability to published MIC values).

The test plates were removed from the incubator and laid out in such a manner that the dilution series was apparent. The MIC value is the concentration of first plate in the dilution series to exhibit no growth (negative). No growth is interpreted as no visible growth or a very faint haze, when compared to control plates. The MIC value is the concentration of the first plate in the dilution series to exhibit no growth (negative). The presence of colonial growth of dermatophytes on the area where dilution was applied is recorded as growth).

\section{UPLC based chromatographic profiling}

Ultra-Performance Liquid Chromatography-Mass Spectrometry (UPLC) is an advanced technique for plant metabolite profiling. ${ }^{16}$ It allows the qualitative identification of a large range of common plant secondary metabolites in a single chromatogram. Therefore, to explore the types of secondary metabolites that could be present the methanolic extract was screened All UPLC separations were carried out on ACQUITY UPLC TM system (Waters) using a reversed phase column Acquity $\mathrm{UPLC} \mathrm{C}_{18}(100 \mathrm{~mm} \times 2.1 \mathrm{~mm})$ (Waters, UK), with $1.7 \mathrm{~m}$ spherical porous particles. The elution was performed using gradient between water and methanol. Separation time was $10 \mathrm{~min}$ and additional $2 \mathrm{~min}$ post run time was required for recondition of the column to initial condi-

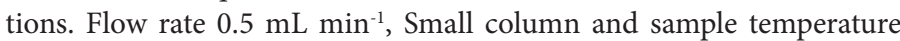
$25^{\circ} \mathrm{C}$ and the injection volume: $2 \mu \mathrm{l}$ were used in all experiments.

\section{HPLC studies on methanolic extracts}

\section{Instrumentation}

The HPLC system used consisted of a Shimadzu LC-10 AD pump, Shimadzu SPD-6AV variable wavelength UV/ Vis detector, and using low dead volume connections, and a A1-450 Dionex integrator (all supplied by Dyson Instruments, Hetton-le-Hole, Tyne \& Wear, UK). Injections were manually using a Rheodyne 7125-injection valve (Anachem, Luton, Beds., UK) fitted with a20 $\mu \mathrm{l}, 50 \mu \mathrm{l}, 1 \mathrm{ml}$ and $2 \mathrm{ml}$ loops for analytical, semi-preparative and preparative scale up, respectively. 


\section{Materials}

ACE-5-C18 (250X4.6mm I.D.), ACE-5-C 18(250X7mm I.D.), ACE-5-C $18(250 \mathrm{X} 22 \mathrm{~mm})$ were used during the study. Mobile phases were prepared by using HPLC-grade methanol, HPLC far-UV grade (Sigma-Aldrich, Poole, and Dorset UK). Water was distilled and doubly de-ionized using and Elgostat option 3 (Vivendi Water Systems, High Wycombe, Bucks., UK), [Methanol-water (90:10, v/v,)] with $0.002 \mathrm{M}$ ammonium formate was used as mobile phase.

\section{RESULTS AND DISCUSSION}

Herbal drugs containing radical scavengers are gaining importance for the treatment of such diseases. Many plants exhibit efficient antioxidant properties attributable to their phenolic constituents. ${ }^{19-22}$ Traditional medicine also serves as remedy for many fungal infections and it is logical to explore the antifungal potential of the extracts and isolated compounds.In the present study A total of three crude methanolic plant extracts, four isolated compounds and eleven semi-purified fractions were tested for in-vitro efficacy, using an agar incorporation method to determine the minimum inhibition concentration (MIC), against the dermatophyte species; T. rubrum, T. mentagrophytes, E. floccusum and C. albicans. The results are tabulated in Table 1, 2, 3 and 4. The MIC value for crude methanolic extracts of T. roxbhurghiana and G. calcicola was found to be $62.5 \mu \mathrm{g} / \mathrm{ml}$ and $31.2 \mu \mathrm{g} / \mathrm{ml}$ against T. rubrum and T. mentagrophytes, whereas methanol extract of $C$. excavata did not show any activity against dermatophytes. The isolated compounds (from methanol extract of Tetractomia roxbhurghiana) angelicin and gallic acid also displayed significant activity against T. rubrum and T. mentagrophytes. Based on the results and literature reports, it may be possible that the

Table 1: MIC values for three Rutaceous crude extracts by agar dilution method

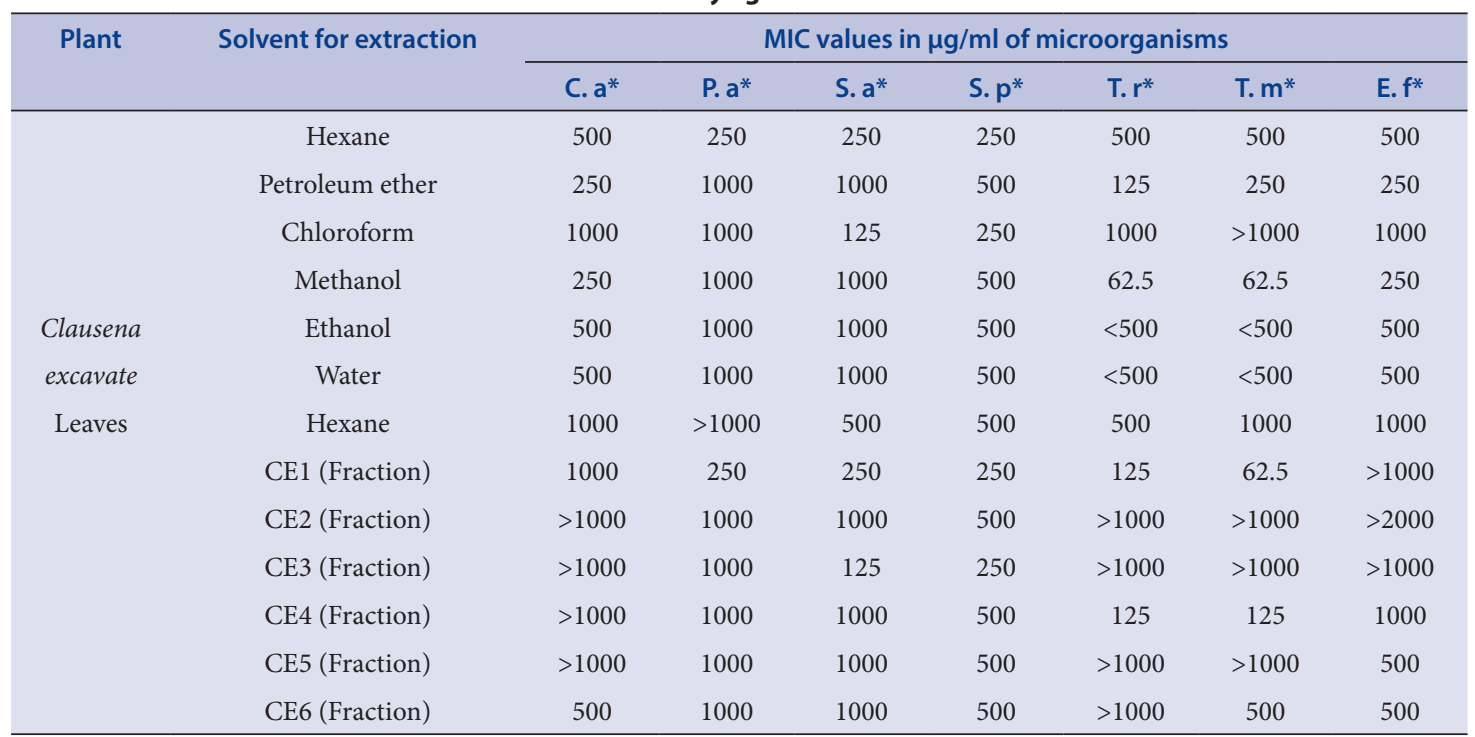

C. $a^{*}$ - Candida albicans; P. $a^{*}$ - Propionibacterium acne; S. $a^{*}$-Staphylococcus aureus, S. $p^{\star}$-Streptococcus pyogenes; T. $r^{\star}-$ Trichophyton rubrum; T. $m^{*}$ - Trichophyton mentagrophytes; E. $f^{*}$ - Epidermatophyton floccusum

Table 2: MIC values of standard drugs, by agar dilution against selected microorganisms

\begin{tabular}{|c|c|c|c|c|c|c|c|}
\hline Standards & \multicolumn{7}{|c|}{ microorganisms MIC in $\mu \mathrm{g} / \mathrm{ml}$} \\
\hline Ketaconazole & 0.04 & 5 & 10 & $<3.91$ & - & - & - \\
\hline Miconazole & 0.08 & 0.63 & 1.25 & - & - & - & - \\
\hline Griseofulvin & 1.25 & 20 & 20 & - & - & - & - \\
\hline Ciclopirox & 5 & 5 & 5 & - & - & - & - \\
\hline Ciclopirox olamine & 5 & 10 & 5 & - & - & - & - \\
\hline Ciprofloxacin & - & - & - & - & $<3.91$ & $<3.91$ & - \\
\hline Gentamycin & - & - & - & - & $<3.91$ & $<3.91$ & - \\
\hline
\end{tabular}

T. $\mathrm{r}^{*}$ - Trichophyton rubrum;

T.m*-Trichophyton mentagrophytes;

E. $\mathrm{f}^{*}$ - Epidermatophyton floccusum

S. $\mathrm{a}^{*}$ - Staphylococcus aureus;

S. $\mathrm{p}^{*}$-Streptococcus pyogens;

C. $\mathrm{a}^{\star}$ - Candida albicans 
ant-fungal activity of T. roxbhurghiana and G. calcicola methanol extracts arose at least in part from angelicin and gallic acid. Out of the eleven semi-purified fractions, GCA2 showed anti-fungal activity. However, the anti-fungal activity of $T$. roxburghiana extract would be worth investigating further.

UPLC provided better resolution as shown in the (Figure 1) compared to routine RP-HPLC. The analysis time was drastically reduced (4 min.) in case of UPLC analysis which proved to be a faster and more economical analytical tool than RP-HPLC (Figure 2) and most importantly the solvent consumption is very high in the case of RP-HPLC due to long run times nearly about 40 minutes. Hyphenation of these techniques to detection systems like NMR would ease and enhance the identification of plant constituents. Use of class separations by LC, particularly using ion-exchange phases can speed up preparative work. Fractions from preparative HPLC may be rapidly monitored. Alternatively, crude extracts can be fractionated by preparative RP-HPLC. The chromatograms shown in demonstrate the high-resolution power and reduced analysis time of UPLC. This is very much proved to be the case not only for rapid monitoring of fractions (Figure 4) but also the very rapid profiling of the crude extracts (Figure 3 ) themselves with similar resolution to that could be obtained on a $25-\mathrm{cm}$ column. The chromatogram shown in the (Figure 3) Proves that it is preferable to run the semi-purified fractions using UPLC rather than crude extracts.

Selection of solvents is to be considered mainly based on solubility of the extracts and volatility of the solvent. Monitoring fraction purity and structural elucidation could be done with LC-NMR-MS ${ }^{23,24}$ using orthogonal LC modes and scale up orthogonal LC modes for isolation of constituents from impure fractions for microbiological and anti-fungal activity testing. It is also logical to extend the testing of the extracts and isolated compound for other biological activities like ant-inflammatory, analgesic, and anti-psoriatic because flavonoids have also been reported to possess a variety of pharmacological activities ${ }^{25}$ including analgesic,

Table 3: MIC values for isolated compounds and semi-purified fractions

\begin{tabular}{|c|c|c|c|c|c|}
\hline \multirow{2}{*}{ Plant } & \multirow{2}{*}{ Isolated Compounds/ Fractions } & \multicolumn{4}{|c|}{ MIC values in $\mu \mathrm{g} / \mathrm{ml}$ of microorganisms } \\
\hline & & C.a & T.r & T.m & E.f \\
\hline \multirow{5}{*}{$\begin{array}{l}\text { Tetractomia } \\
\text { roxburghiana }\end{array}$} & Angelicin & 1000 & 125 & 62.5 & $>1000$ \\
\hline & Swertisin & $>1000$ & $>1000$ & $>1000$ & $>200$ \\
\hline & g-asarone & $>1000$ & $>1000$ & $>1000$ & $>1000$ \\
\hline & Gallic acid & $>1000$ & 125 & 125 & 1000 \\
\hline & GCA1 (Fraction) & $>1000$ & 500 & 500 & 1000 \\
\hline \multirow{4}{*}{$\begin{array}{c}\text { Glycosmis } \\
\text { calcicola }\end{array}$} & GCA2 (Fraction) & 1000 & 125 & 62.5 & $>1000$ \\
\hline & GCA3 (Fraction) & 1000 & $>1000$ & 500 & 1000 \\
\hline & GCA4 (Fraction) & $>1000$ & 500 & 250 & 1000 \\
\hline & GCA5 (Fraction) & 1000 & $>1000$ & 1000 & 500 \\
\hline \multirow{6}{*}{$\begin{array}{l}\text { Clausena } \\
\text { excavata }\end{array}$} & CE1 (Fraction) & $>1000$ & 1000 & 1000 & 500 \\
\hline & CE2 (Fraction) & 1000 & 2000 & 1000 & $>100$ \\
\hline & CE3 (Fraction) & $>1000$ & 1000 & $>1000$ & 500 \\
\hline & CE4 (Fraction) & 500 & $>1000$ & 500 & $>1000$ \\
\hline & CE5 (Fraction) & $>1000$ & $>1000$ & $>1000$ & 500 \\
\hline & CE6 (Fraction) & 500 & $>1000$ & 500 & 500 \\
\hline
\end{tabular}

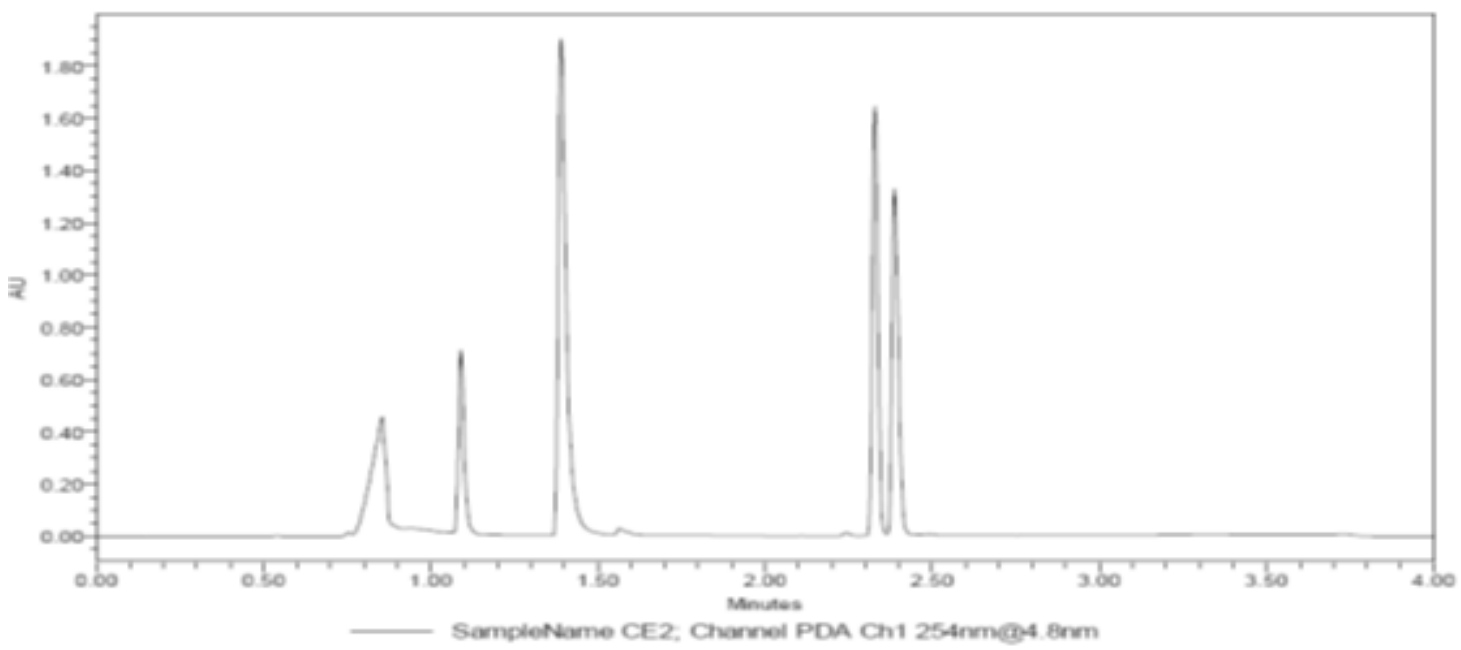

Figure 1: UPLC profile of CE 2 fraction collected from preparative HPLC of methanolic leaf extract of Clausena excavata with a short column, C18 5 X $2.0 \mathrm{~mm}$; conc. $0.5 \mathrm{mg} / \mathrm{ml}$, flow rate: $0.5 \mathrm{ml} / \mathrm{min}$; Injection volume $2 \mu \mathrm{l}$, UV detection $\lambda$ max: $254 \mathrm{~nm}$. 


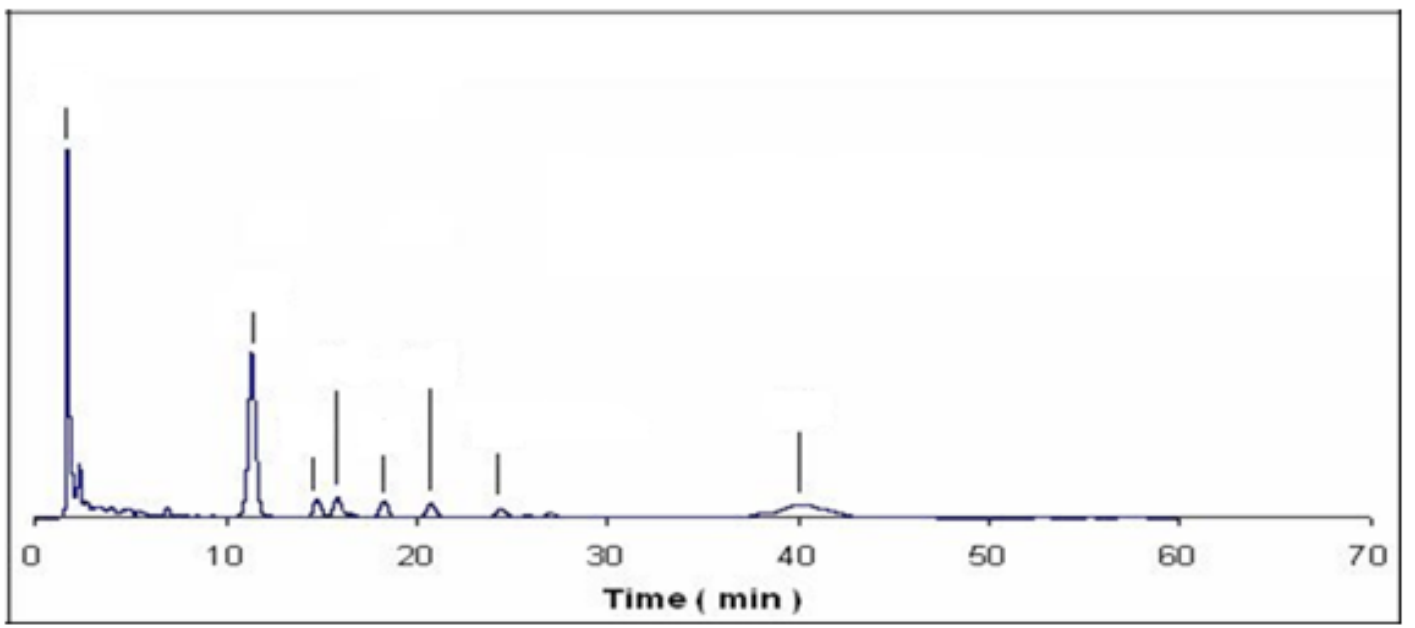

Figure 2: HPLC profile CE2 fraction (CE 2) of Clausena excavata with a mobile phase of methanol-water (90:10, v/v) with $0.002 \mathrm{M}$ ammonium formate C18 $(250 \times 4.6 \mathrm{~mm}$ ) sample concentration $0.5 \mathrm{mg} / \mathrm{ml}$, injection volume $20 \mu \mathrm{l}$, flow rate: $1 \mathrm{ml} / \mathrm{min} ; \lambda \mathrm{max}: 254$ $\mathrm{nm} . \mathrm{ax} 254 \mathrm{~nm}$

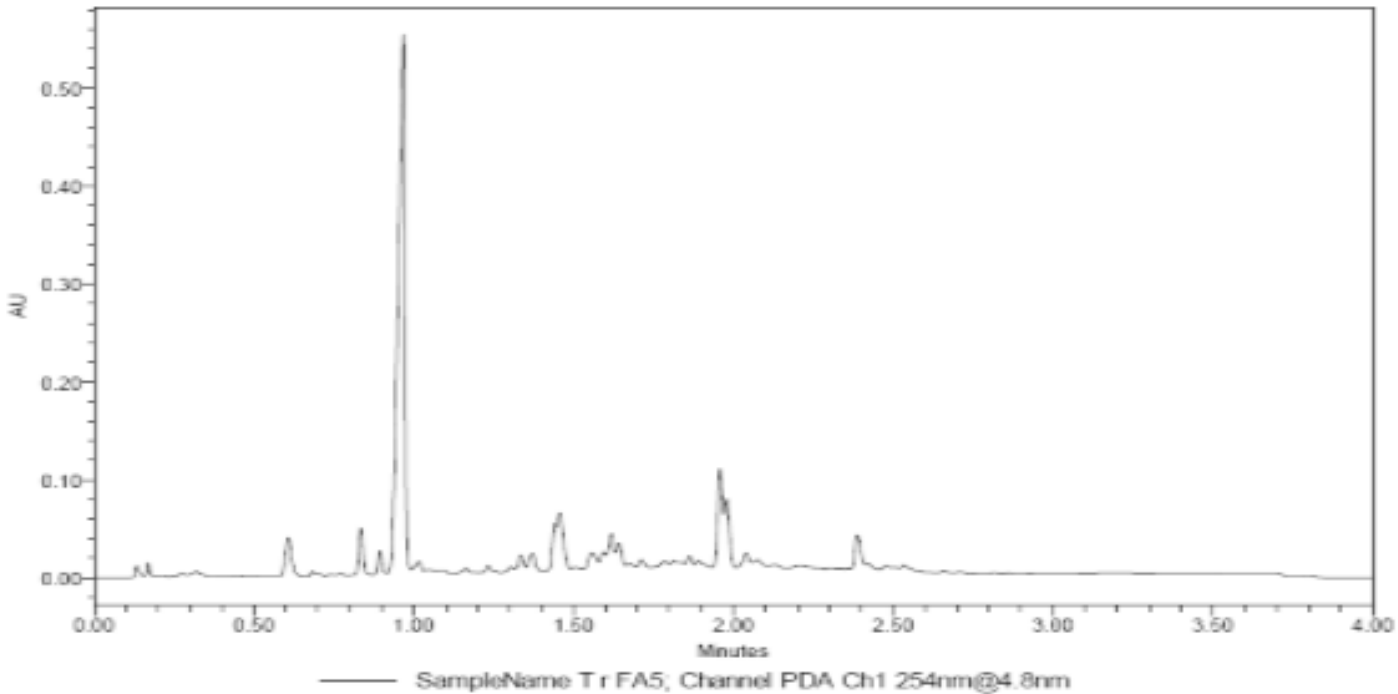

Figure 3: UPLC profile of TRFA 5 fraction collected from flash column (methanolic leaf extract of Tetractomia roxburghiana) with a short column, C18 5 X $2.0 \mathrm{~mm}$; conc. $0.5 \mathrm{mg} / \mathrm{ml}$, flow rate: $0.5 \mathrm{ml} / \mathrm{min}$; Injection volume $2 \mu \mathrm{l}$, UV detection at $\lambda$ max: $254 \mathrm{~nm}$.

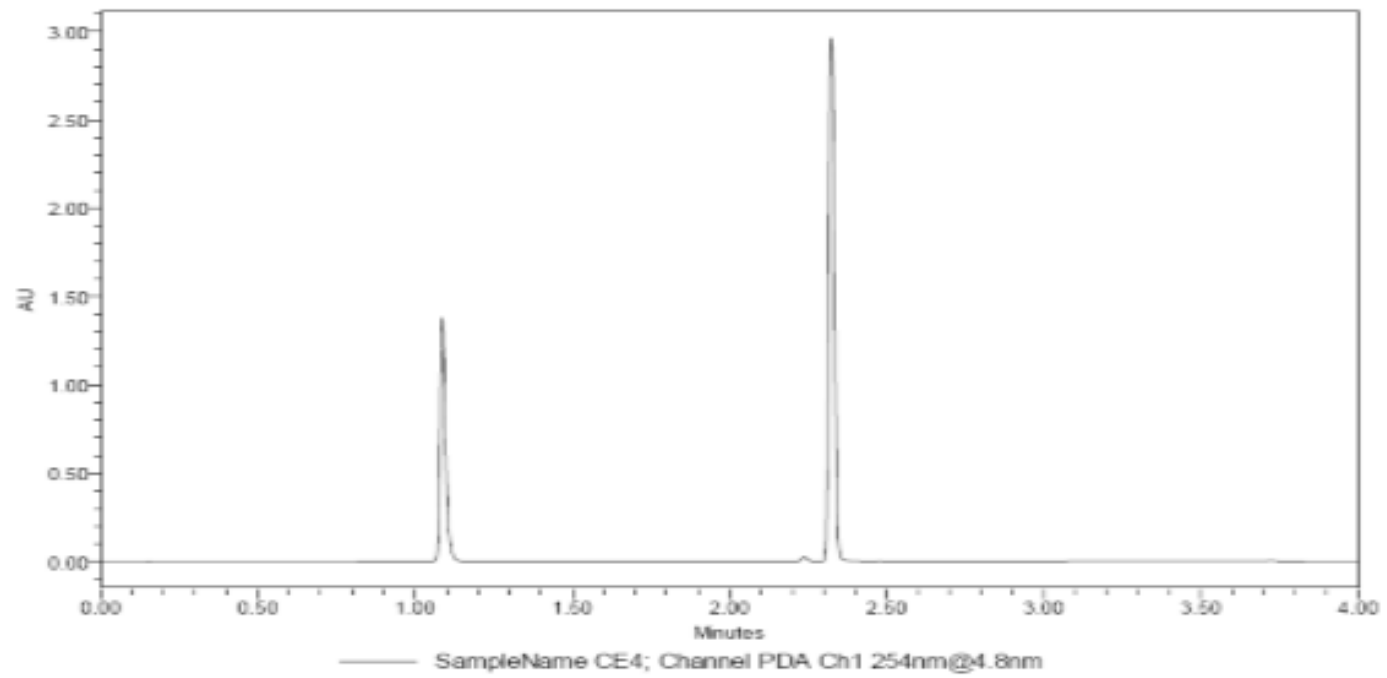

Figure 4: UPLC profile of CE 4 fraction collected from preparative HPLC of methanolic leaf extract of Clausena excavata with a short column, C18 $5 \times 2.0 \mathrm{~mm}$; sample conc. $0.5 \mathrm{mg} / \mathrm{ml}$, flow rate: $0.5 \mathrm{ml} / \mathrm{min}$; Injection volume $2 \mu \mathrm{l}$, UV detection at $\lambda \mathrm{max}: 254 \mathrm{~nm}$. 
ant-inflammatory, anti-microbial, anti-histaminic, anti-cancer, antidiabetic

The samples, which were analysed by UPLC, were the ones, which had failed to give a positive match with library spectra when using accurate mass MS because they were mixtures. It was confirmed that this was very much the case for these fractions which had in general been from the peaks in between the major peaks.

All the LC approaches to monitoring fraction purity (RP-HPLC for RPHPLC-NMR, ion exchange LC, UPLC) were successful in terms of being viable means of rapidly reviewing the composition of collected fractions. From the above chromatograms, it can be observed that better resolution (when compared to RP-HPLC) could be achieved within a short analysis time. Thus UPLC could serve as fast and economical analytical tool for isolation and identification of complex plant mixtures. Ultimately, the use of UPLC-NMR might improve methods further with better resolution to accompany the NMR. This is the first time, we have established the Minimum inhibitory concentration values of three methanolic extracts and isolated components against dermatophytes and confirmed their anti-fungal potential. This future work would include scale up of the developed analytical gradient method for Clausena excavata. to a preparative method for isolation and identification of plant constituents from rutaceous extracts and also the use of appropriate straight phase system for further separation of unresolved mixtures (impure fractions). ${ }^{26,27}$ Straight phase could help in separation of compounds, which were not resolved using reverse phase systems.

\section{CONCLUSION}

In conclusion, our findings reveal that UPLC is a simple and economi $\neg$ cal tool than RP-HPLC for the identification of plant secondary metabolites in the semi-purified fractions. However, in the purification of unresolved component mixtures further investigation is required. The present study also confirmed the anti-fungal activity against dermatophytes Trichophyton rubrum, Trichophyton mentogra $\neg$ phytes and the observed antifungal activity may be due to the presence of angelecin and gallic acid present in biologically active extracts.

\section{ACKNOWLEDGEMENT}

The author acknowledges department of Pharmacy, K L University for providing resources for the research work. The author also acknowledges University of Sunderland for providing support for analytical methodologies.

\section{CONFLICT OF INTERESTS}

The authors declare that they have no competing interests associated with this study.

\section{ABBREVIATIONS USED}

I.D: Internal diameter; $\mathrm{cm}$ : centimeter; $\mathrm{mm}$ : millimeter; UPLC: Ultra Performance Liquid Chromatography; RP-HPLC: Reverse Phase-High Performance Liquid Chromatography; M: meter; ROS: Reactive Oxygen Species; MIC: minimum inhibitory concentration; ml: milliliter; SDA: Sabouraud Dextrose Agar; DMSO: dimethyl sulfoxide; $\mu$ g: microgram; $\mu \mathrm{l}$ : microliter; CFU: Colony Forming Unit; TVAC: total viable aerobic Count; UV: Ultraviolet; v/v: volume per volume; NMR: Nuclear Magnetic Resonance; $\mathrm{nm}$ : nanometer.

\section{REFERENCES}

1. Manosroi A, Saraphanchotiwitthaya A. In-vivo immunomodulating activ ity of wood extracts from Clausena excavata Burm.f. J Ethnopharmacol. 2005;102(1):5-9 http://dx.doi.org/10.1016/j. jep.2005.04.033 PMid:16023813.
2. Manosroi A, Saraphanchotiwitthaya A. Immunomodulatory activities of Clausena excavata Burm.f.wood extracts. J Ethnopharmacol. 2003;89(1):155-60 http:// dx.doi.org/10.1016/ S0378-8741(03)00278-2.

3. Rahman MT, Alimuzzaman M, Shilpi JA, and Hossain MF. Anti-nociceptive activity of ethanolic extract of Clausena excavata leaves. Fitoterapia. 2002;73(78):701-3. http://dx.doi. org/10.1016/S0367-326X(02)00211-3. https://doi. org/10.1016/S0367-326X(02)00211-3.

4. Shiow $\mathrm{CH}$, Pei IW, Tian SW. Carbazole alkaloids from Clausena excavata and their biological activity. Phytochemistry. 1996;43(1):133-40. http://dx.doi. org/10.1016/0031-9422(96)00212-97).

5. Randrianarivelojosia $\mathrm{M}$, Rebarison $\mathrm{H}$. Plants traditionally prescribed to treat tazo (malaria) in the eastern region of Madagascar. Malaria Journal. 2003;2(1). http:// dx.doi. org/10.1186/1475-2875-2-25 PMid:12921540 PMCid:184444. https://doi. org/10.1186/1475-2875-2-25

6. Wu Tian-Shung, Huang Shiow-Chyn. Chemical and antiplatelet aggregative investigation of the leaves of Clausena excavata. Phytochemistry. 1993;32(2):449-51. http://dx.doi.org/10.1016/ S0031-9422(00)95013-1.

7. Tian-Shung Wu, Shiow-Chyn Huang, Pei-Lin Wu. Carbazole-pyrano coumarin dimer and binary carbazole alkaloid from Clausena excavata Tetrahedron Lett. 1996;37(43):7819-22. http://dx.doi.org/10.1016/0040-4039(96)01741-88).

8. Masuda T, Inazumi A, Yamada Y, William G. Padolina WG, Hiroe Kikuzaki H, Nakatani N. Anti-microbial phenylpropanoids from Piper sarmentosum. Phytochemistry. 1991;30:3227-8. http:// dx.doi.org/10.1016/0031-9422(91)83180-S. https:// doi.org/10.1016/0031-9422(91)83180-S.

9. Tian-Shung Wu, Shiow-Chyn Huang, Pei-Lin Wu, Che-Ming Teng. Carbazole alkaloids from Clausena excavata and their biological activity. Phytochemistry. 1996:43(1):133-40. http:// dx.doi.org/10.1016/0031-9422(96)00212-99).

10. Simonsen HT, Adsersen A, Smitt UW, Strasburg D, Jaroszewski JW. Methoxyflavones from Melicope borbonica and M. obscura. Biochem. Syst. Ecol. 2003;31(3):327-30. http:// dx.doi.org/10.1016/S0305-1978(02)00158-8. https:// doi.org/10.1016/S0305-1978(02)00158-8

11. Bowen $\mathrm{IH}$, Osborne SJ. Phytochemical studies in the genus Maclurodendron (Rutaceae): furoquinoline alkaloids. J Pharm Pharmacol. 1998;50:233-37. http:// dx.doi.org/10.1111/j.2042-7158. 1998.tb02433.

12. Bowen I H, Perera KPWC. Alkaloids, coumarins and flavonoids of Micromelum zeylanicum. Phytochemistry. 1982;21(2):433-7. http://dx.doi.org/10.1016/S00319422(00)95283-X. https://doi.org/10.1016/S0031-9422(00)95283-X.

13. Bowen $I H$, Patel YN. Acridone alkaloids from Pleiospermium alatum. Phytochemistry 1986;25(2): 429-31. http://dx.doi. org/10.1016/S0031-9422(00)8549531)

14. Repetto MG, Llesuy SF. Antioxidant properties of natural compounds used in popular medicine for gastric ulcers. Braz J Med Biol Res. 2002:35(35):523-4. PMid: 1201193620) https://doi.org/10.1590/s0100-879x2002000500003.

15. Kalemba D, Kunicka A. (2003) Anti-bacterial and anti-fungal properties of Ajmal AM, Abul FM, Fahad AM, Abou-Tarboush FM, Al-Anazi KM, Wabaidur SM, et al. Assessment of biological activity and UPLC-MS based chromatographic profiling of ethanolic extract of Ochradenus arabicus, Saudi J of Biological Sciences. 2016:23(2):229-36. https://doi.org/10.1016/j.sjbs.2015.02.010 PMid:26981004 PMCid:PMC4778516

16. Emel S, Saadet G. Alterations in brain antioxidant status, protein oxidation and lipid peroxidation in response to different stress models Behav Brain Res. 2004;155(2):241-8. http://dx.doi.org/10.1016/j.bbr.2004.04.022 PMid:15364483. https://doi.org/10.1016/j.bbr.2004.04.022.

17. Chatterjee SN, Sanjiv Agarwal. Liposomes as membrane model for study of lipid peroxidation Free Radical Bio Med. 1988;4(1):51-72

18. Ilya I. Ivanov. A relay model of lipid peroxidation in biological membranes. Journal of Free Radical Bio Med. 1985;1(4):247-53. http://dx.doi.org/10.1016/07485514(85)90128-X. https://doi.org/10.1016/0748-5514(85)90128-X.

19. Kumaraswamy $Y$, Byers M, Cox PJ, Sarkar SD. Isolation, structure elucidation, and biological activity of flavone 6-C-Glycosides from Alliaria petiolata. Chemistry of Natural Products. 2004;122-8.

20. Sakagami H, Satoh K. Prooxidant action of two anti-oxidants: ascorbic acid and gallic acid. Anticancer Research. 1997;17(1A):221-4. PMid:9066655. PMid:9066655.

21. Kroes $\mathrm{BH}$, Van den Berg AJJ, Quarles Van Ufford $\mathrm{HC}$, Van Dijk $\mathrm{H}$. Antiinflammatory activity of gallic acid. Planta Medica. 1992;58:499-504. http://dx.doi.org/10.1055/s-2006-961535, PMid:1336604. https://doi. org/10.1055/s-2006-961535

22. Luisa M, Eleonora LP, Giulia M, Christine M, Francarosa B, Giuseppe F, et al. Synthesis of angelicin heteroanalogues: preliminary photobiological and pharmacological studies II Farmaco. 1998:53:602-10.

23. Zhao Y, Nookandeh A, Schneider B, Sun X, Schmitt B, Stiokigt J Lignans from Torreya jackii identified by stopped-flow high-performance liquid chromatography-nuclear magnetic resonance spectroscopy. Journal of Chromatgraphy A 1999;837:83-91. https://doi.org/10.1016/S0021-9673(99)00050-3.

24. Xin, L, Xinjie Z, Changmin Bai, Chunxia Zhao, Guo Lu, Guowang

25. Xu. LC-MS-based metabonomics analysis. Journal of Chromatography B. 2008;866:64-76. https://doi.org/10.1016/j.jchromb.2007.12.017 https://doi. org/10.1016/j.jchromb.2007.10.022 PMid:17983864. 
26. Havsteen B. Flavonoids, a class of natural products of high pharmacological potency. Biochemical Pharmacology. 1983;32:1141-8. https://doi.org/10.1016/00062952(83)90262-9.

27. Hostettmann K, Wolfender J.L, Ndjoko K Liquid chromatography with ultravio- let absorbance-mass spectrometric detection and with nuclear magnetic resonance spectroscopy: a powerful combination for the on-line structural investigation of plant metabolites. Journal of Chromatography A. 2003;1000:437- 55 https://doi.org/10.1016/S0021-9673(03)00303-0.

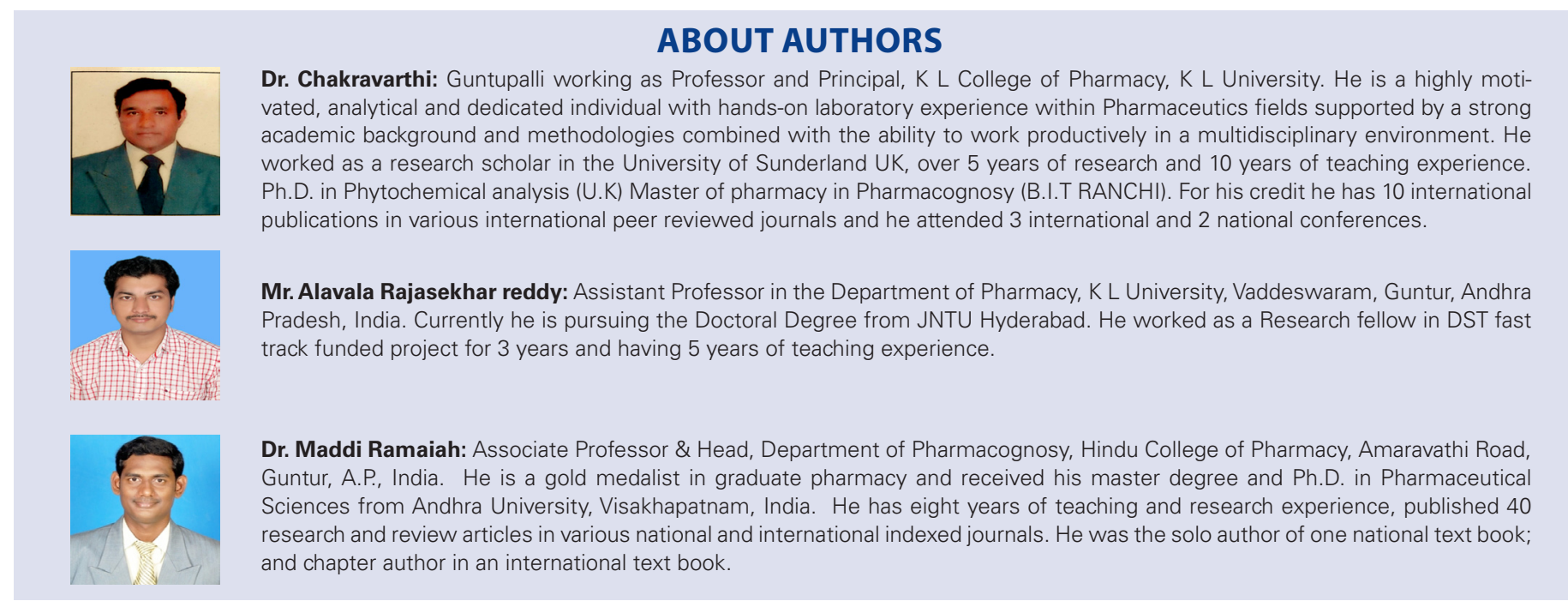

Cite this Article: Chakravarthi G, Rajasekhar AR, Ramaiah M. Assessment of Biological Activity and Comparison of UPLC and RP-HPLC Chromatographic Profiles of Clausena excavata Burm.F. Pharmacogn J. 2017;9(2):185-91. 